\title{
Clase política y sector bancario en la Argentina de entreguerras: el caso del Banco Español y del Río de la Plata
}

\section{Political Class and Banking Sector in Argentina between the Interwar Years: the Case of Banco Español y del Río de la Plata}

\author{
Carlos Newland $^{1, *}$ * (D) 0000-0001-7522-7347
}

${ }^{1}$ ESEADE Instituto Universitario, Buenos Aires, Argentina.

* Correspondencia: newland@eseade.edu.ar

Resumen. Este trabajo analiza la relación entre la clase política y el sistema bancario argentino entre la primera y segunda guerras mundiales, a través del caso del Banco Español y del Río de la Plata. Se describe la muy íntima relación entre diversos políticos influyentes que recibieron un trato privilegiado de un establecimiento privado que a su vez dependía para su existencia de la ayuda pública. Esta fue una clara muestra de capitalismo de amigos, estudiada aquí a través de diversas fuentes, entre las que destaca documentación interna del banco.

Palabras clave: finanzas; bancos; corrupción.

Abstract. This paper analyzes the relationship between politics and the Argentine banking system between the first and second world war, through the case of the Banco Español y Rio de la Plata. The intimate connection with the financial institution and various influential politicians who received privileged treatment

CÓMO CITAR: Newland, C. (2020). Clase política y sector bancario en la Argentina de entreguerras: el caso del Banco Español y del Río de la Plata. América Latina en la Historia Económica, 27(2), e1028. DOI: 10.18232/alhe.1028 
is described. Al the same time the Banco Español depended for its existence on public aid. This seems a very a clear-cut case of crony capitalism, which is studied through diverse sources, and specially through internal documentation.

Key words: finances; Banks; credits.

JEL: N26

Recibido: 25 de septiembre de 2018.

Aceptado: 25 de febrero de 2019.

Publicado: 16 de diciembre de 2019.

\section{INTRODUCGIÓN}

La relación entre la clase política y la banca pública suele ser intensa tanto en Argentina como en cualquier país de América Latina. 1 Esto no sorprende ya que la política exige financiamiento que suele originarse, en buena medida, en grupos empresariales privados. Una forma rápida de repago de estas contribuciones es a través de un tratamiento privilegiado en la banca estatal controlada por los gobiernos. Por otra parte, existen los intereses directos de los mismos políticos con sus propios emprendimientos y grupos económicos relacionados. Por estas razones es imprescindible para los gobernantes controlar los directorios de los bancos públicos, colocando allí a individuos dóciles a sus indicaciones y sugerencias. Uno de los casos más notorios es el del Banco de la Nación Argentina (Banco Nación), el mayor establecimiento financiero del país, cuyos escandalosos tratamientos especiales son públicos $2^{2} \mathrm{El}$ descubrir cómo funcionan los mecanismos de subordinación de lo financiero a lo político se hace difícil cuando la investigación es de índole histórica, aunque pueden mencionarse dos testimonios relevantes: cuando, en 1930, Raúl Prebisch, economista, participó como funcionario del gobierno militar golpista del general José Uriburu, hizo un intento por lograr que se designara un directorio representativo (presumiblemente independiente) en el Banco Nación. Aunque Prebisch contó con el apoyo del ministro de Hacienda, Enrique Pérez, la iniciativa sería pronto bloqueada por el vicepresidente en favor de integrantes de la clase terrateniente (Mallorquín, 2006, pp. 65-66) $\mathrm{S}^{3}$ Otro caso es el de Mario Martínez Casas, un abogado cordobés a quien el presidente Juan Domingo Perón convocó para ocupar la jefatura del Banco Nación en 1949. Mario Martínez puso como condición para asumir que el establecimiento pudiera actuar con autonomía, lo que en un principio fue aceptado. Así, el banco comenzó a otorgar créditos con criterios profesionales y de promoción económica sin injerencia del poder ejecutivo. No obstante, según Martínez (1957, pp. 107-126), la experiencia tendría corta duración: pronto los trámites crediticios comenzaron a ser bloqueados requiriendo que el Banco Central los convalidara, lo que

\footnotetext{
${ }^{1}$ El ministro de Economía de Brasil, Paulo Guedes, declaró que la banca pública en Brasil estuvo en el pasado al servicio de la corrupción, las alianzas políticas, y de la ayuda a empresarios amigos del poder. P. Guedes, "La administración de Bolsonaro apunta contra la banca pública”, La Voz del Mundo, 8 de enero de 2009. Recuperado de https://www.lavoz.com.ar Sobre la cuestión general de relación entre sector financiero, sectores políticos y marco regulatorio, véase Calomiris y Haber (2014).

${ }^{2}$ Como muestra véanse G. Cherasny, “Corrupción en el Banco Nación”, El Ojo Digital, 21 de julio de 2010. Recuperado de http://www.elojodigital.com, y "El ex presidente del Banco Nación y un amigo de Máximo Kirchner serán indagados por los créditos para Lázaro Báez”, Infobae, 8 de junio de 2017. Recuperado de https://www.infobae.com

${ }^{3}$ Se trataba de Enrique Santamarina, hermano de Antonio y de Jorge Santamarina, cuyos casos se tratan más adelante.
} 
hacía con mucha demora, cuando ya esos préstamos no eran viables. Al mismo tiempo, Martínez Casas recibió la visita de algunos gobernadores que le advirtieron que había acusaciones en su contra circulando en la casa de gobierno. Al final, renunciaría a su cargo.

Es indudable que el Banco Nación ha estado cargado de créditos otorgados con criterios políticos a lo largo de su historia. Pero encontrar y analizar la documentación relacionada es difícil (aunque no imposible), ya que no hay acceso público directo a sus archivos, ni facilidades para investigarlos. Este artículo procura estudiar la misma cuestión a través de una entidad privada de gran dimensión, el Banco Español del Río de la Plata (Banco Español), la que estuvo vinculada y era en gran medida dependiente del Banco Nación gracias a su ayuda financiera. Sobre su importancia puede mencionarse que, en 1935, hacia el final del periodo de entreguerras, el Banco Español representaba $9 \%$ de los depósitos bancarios totales de Argentina, cifra que lo hacía la mayor institución financiera privada del país. Sólo era superada por el dominante Banco Nación, que absorbía 75 \% de los depósitos (Estadística bancaria de año 1935, 1936, p. 21).

Cabe mencionar que el Banco Español fue propenso a atender las necesidades de la clase política de la cual dependía su financiamiento. Esta situación fue sostenida por la acción de los múltiples beneficiarios que generaba el sistema: tanto los administradores y propietarios de la entidad crediticia, como por un conjunto de legisladores y miembros del poder ejecutivo de varios partidos políticos. La contraparte implícita de la ayuda oficial que recibía el establecimiento fueron créditos blandos otorgados a personajes influyentes o sus empresas, créditos tendentes en gran medida a la morosidad. Es posible investigar el Banco Español debido a que parte de su documentación interna fue depositada en la Biblioteca Tornquist del Banco Central Argentino, luego de que el establecimiento financiero quebrara hacia 1986. El tema aquí tratado es relevante en cuanto a las magnitudes económicas involucradas: el pago que hizo el gobierno por adquirir los créditos morosos de los bancos privados en 1935 quizá equivalete hasta un $6 \%$ del producto bruto interno (Della Paolera y Taylor, 2003, pp. 285-287). Del monto total transferido alrededor de la mitad correspondió al Banco Español. En este artículo se analizará la vinculación entre miembros de la clase política y el Banco Español durante buena parte del periodo de entreguerras, un lapso histórico clave, tanto por incluir la Gran Depresión, como la creación del Banco Central, acto que no fue ajeno a la trama descrita.

\section{El NAGimiento y DESARRollo del BANCo EsPaÑol}

En sus primeras décadas de vida el Banco Español se mostró como una organización eficiente e innovadora que realizó sus funciones financieras de manera eficiente con un notable crecimiento que aprovechaba el desarrollo económico de Argentina en su época de oro. La institución fue creada en Buenos Aires en 1886 con el aporte de capital de 50 socios liderados por el uruguayo Augusto Coelho, que se desempeñaría como su gerente general hasta 1913.4 Pronto contaría con 550 accionistas, en buena medida de origen español, lo que implicaba tanto una atomización de sus propietarios como una especial relación con España $5^{5}$ La institución se distinguió entonces por sus prácticas comerciales innovadoras y su solidez en cuanto a respaldo en reservas líquidas. Su

\footnotetext{
${ }^{4}$ Dos estudios recientes que cubren la historia del Banco Español son Iglesias (2012) y Regalsky e Iglesias (2015). La primera historia (semioficial) de la entidad fue la de J. A. Fernández (1912). Para una historia institucional, véase Banco Español del Río de la Plata (1986).

${ }^{5} \mathrm{El}$ estatuto del banco determinaba que el presidente del directorio debía ser de nacionalidad española.
} 
fortaleza se hizo patente durante la crisis iniciada en 1890, ya que fue la única entidad privada junto con el Banco de Londres y Río de la Plata- que no debió cerrar sus puertas. Para principios del siglo xx el banco experimentó un gran aumento tanto en depósitos como en préstamos, transformándose en la segunda entidad local, sólo precedida por el Banco Nación. Para 1910 poseía 41 sucursales en Argentina, habiéndose internacionalizado con ocho sucursales en Europa y una en Brasil. En ese año su patrimonio neto llegaba a unos 100000000 de pesos, una cifra enorme comparada con los 3000000 con que había contado en el momento de su fundación. En ese momento la entidad comenzó a sufrir la competencia causada por la expansión del Banco Nación, del Banco de la Provincia de Buenos Aires, y del Banco de Italia y del Río de la Plata. Ello le causó una pérdida de cuota de mercado, lo que demandaba un reajuste organizacional, mediante un aumento en su eficiencia interna y un replanteo de la necesidad de las múltiples y costosas sucursales en el exterior. Sin embargo, la reacción de sus directivos fue la de bajar la exigencia en los requisitos exigidos a los deudores para aumentar su número, lo que iría empeorando la calidad de su cartera crediticia.

A esta situación se sumó la crisis causada por el inicio de la Gran Guerra, que implicó una caída de los depósitos de muchas entidades bancarias. Por ello, entre fines de 1914 y principios de 1915 el Banco Nación auxilió a las entidades financieras con dificultades bajo la forma de redescuentos que cubrían situaciones de iliquidez. En ese momento, el Banco Español recibió una fuerte ayuda, pero con características distintas a las que percibiría en el futuro: los fondos los obtuvo y devolvió en un lapso corto y pagó por ellos una tasa de interés cercana a la de mercado. El impacto negativo causado por el conflicto mundial se vio agravado en el banco por una enorme pérdida generada por la sucursal de Río de Janeiro, que no había sido controlada de manera adecuada en sus operaciones $5^{6}$ y por un emprendimiento empresarial para desarrollar servicios de trasporte marítimo que resultó en un fracaso. Estos quebrantos, junto con un aumento de los deudores morosos e incobrables, no fueron reflejados en los estados contables, que seguían mostrando una situación patrimonial aceptable, junto con altas utilidades y dividendos. La fragilidad del establecimiento se haría pública y, en consecuencia, se registraría una baja valuación bursátil y una caída de depósitos.7 Hacia 1919 el banco reconocía en su memoria anual que había estado otorgando créditos con excesiva liberalidad y decidió que su balance comenzara a incluir información sobre la acumulación de propiedades de hipotecas ejecutadas y sobre la morosidad en general. En ese año, del total de los créditos otorgados, alrededor de una tercera parte presentaba características de incobrabilidad (Banco Español del Río de la Plata, 1919).

Después de finalizada la contienda mundial el establecimiento logró una cierta recuperación y para 1920 sus depósitos superaban los niveles que había tenido antes de la guerra. Sin embargo, su situación estructural no había cambiado y una crisis estallaría a fines de 1923, cuando se produjo una fuerte pérdida de depósitos, por lo que la entidad tuvo que requerir un gigantesco redescuento de 125000000 de pesos al Banco Nación. Fue necesario entonces que los directivos sinceraran la situación haciendo una fuerte reducción en el capital y las reservas. Esta circunstancia fue presentada y el cambio patrimonial fue aprobado en una asamblea extraordinaria realizada el 2 de febrero de 1924; y en donde también se hizo público que la entidad ahora dependía del auxilio del Banco Nación, cuyos aportes triplicaban el patrimonio neto real del banco. En el informe del

\footnotetext{
${ }^{6}$ Esta situación se reconoció en el informe presentado a los accionistas en asamblea general extraordinaria (Banco Español y del Río de la Plata [BERP], 1924-1935, 2 de febrero de 1924, pp. 233-314). Los libros originales del banco se encuentran en la Biblioteca Tornquist, Banco Central de la República Argentina.

${ }^{7}$ Hacia 1915, el valor bursátil sólo representaba $60 \%$ de su valor contable.
} 
directorio leído en la asamblea se recordaba que el banco estatal siempre había socorrido al Banco Español con fondos incluso en exceso de sus necesidades. En un momento apoteósico de la reunión se pidió a los asambleístas ponerse de pie en homenaje al Banco Nación:

lo que se hace en medio de manifestaciones de simpatía, penetrando en el recinto el señor Presidente del Establecimiento [Banco Nación], Dr. Rafael Herrera Vegas, quien después de agradecer el espontaneo homenaje tributado a la Institución que representa declara los propósitos de solidaridad y adhesión hacia este Establecimiento que inspiraron la actitud de aquella Institución exhortando por fin a españoles y argentinos para que guiados de un mismo y noble anhelo, colaboren en la restauración de los viejos prestigios de esta Casa (Banco Español y del Río de La Plata [BERP], 1924-1935, 2 de febrero de 1924, p. 311).

Con su aporte, el Banco Nación anclaría una suma millonaria en el Banco Español, fondos que en teoría estaban respaldados por sus préstamos, que deberían haber contado con una cierta liquidez ${ }^{8}$ Pero el monto aportado estaba en realidad inmovilizado, ya que correspondía a créditos morosos e insolventes. En este momento el Banco estaba funcionando con un patrimonio neto negativo, un hecho destacado por Raúl Prebisch, quien además remarcaría que los miembros del directorio del Banco Nación solicitaban favores a cambio de la ayuda otorgada, en especial créditos riesgosos sin garantías, créditos que la institución oficial no quería conceder de manera directa para no quedar expuesta en materia legal. Raúl Prebisch señalaría que "ahí le metían todo crédito malo" (Mallorquín, 2006, p. 38). Rafael Herrera Vegas era uno de los beneficiados por este esquema. Su hermano y socio, Marcelino Herrera Vegas recibiría del Banco Español un crédito por 1750000 pesos 9 mientras que su esposa, María Antonia Pereyra Iraola, sería deudora de 300000 pesos de la misma institución.10 Juan B. Justo (1927, p. 8), senador socialista, denunciaba en el Congreso el tipo de relación íntima generada entre las dos instituciones:

la mayor parte [de los redescuentos otorgados por el Banco Nación] corresponden a una institución privada de esta plaza, al Banco Español del Río de la Plata, que llegó a la real y verdadera bancarrota, que dilapidó en especulaciones indecentes todo su capital y que ha sido mantenido a flote gracias al favor extraordinario del Banco de la Nación, que le ha prestado hasta 130000000 al cuatro y medio por ciento, cuando la Nación está pagando por sus deudas el siete y medio y el ocho por ciento. iY ese banco tiene ahora casi tantos depósitos como antes de su cuasi bancarrota, continúa redescontando de igual forma del Banco Nación! Este tiene en ese banco particular una especie de sucursal que no le produce más que gastos, que pesa sobre toda la economía del país, y le paga menos interesas que los que paga la Nación por sus propios créditos.

\footnotetext{
${ }^{8}$ Los redescuentos se otorgaban contra documentos de los deudores del Banco Español.

${ }^{9}$ Marcelino Herrera Vegas también tenía un crédito del Banco Nación por 6000000 de pesos, a una tasa de interés inferior a la de mercado. Senado de la Nación (1926, p. 6). Véase también BERP (1924-1935, 26 de diciembre de 1934, p. 207).

${ }^{10}$ Para 1941 consta que tenía un crédito moroso con el Banco Español trasferido al Instituto Movilizador por 326 611 pesos. Banco Crédito Español del Río de La Plata (BCERP, 1936-1941, 26 de junio de 1941, p. 14). También consta allí que María Antonia Pereyra Iraola tenía deudas con el Banco Nación y el Banco Provincia.
} 
Un artículo de una publicación especializada de la época hacía eco de la denuncia del senador al mencionar que el Banco Español se encontraba desprestigiado, debiendo ser auxiliado por el Banco Nación repetidas veces. Lo más grave era que presentaba documentos falsos de créditos otorgados a terceros para la obtención de los redescuentos de la entidad pública. Por otra parte, la gestión de la institución era inefectiva y sin capacidad de gestión financiera (Falta de garantía, 1927, pp. 1-3). De igual manera, denunciaba que el Banco Español manipulaba los datos contables, fraguando los balances para ocultar sus créditos incobrables (¿Banqueros?, 1927, pp. 11-12). Años después, en 1935, José Luis Pena, diputado socialista, expresó ante el congreso, y en términos semejantes, que la situación del banco no había cambiado, sino agravado por la influencia cada vez más fuerte de políticos en la gestión del banco, lo que lo hacía realizar inversiones disparatadas y efectuar gastos ridículos. En el Banco Español, afirmaba, se "hacen cosas, pero muy malas, malísimas" (Banco Central de la República Argentina [BCRA], 1972, II, p. 997).

El Banco Nación se encontraba, hacia 1930, al inicio de la Gran Depresión, con un problema estructural, puesto que muchos de sus recursos líquidos habían sido entregados al Banco Español (y en menor medida a otras tres instituciones financieras). Fue en 1931 que el gobierno de facto decidió utilizar la ley de redescuentos de 1914 por la que se permitía endosar préstamos a la Caja de Conversión recibiendo fondos líquidos a cambio. Así, la entidad pública aliviaba su cartera a la vez que se intentaba renovar la confianza en el sistema bancario en un momento en que se temía una corrida general. De cualquier forma, los responsables de los créditos seguían siendo en forma primaria los bancos que habían otorgado los créditos. Para ellos la situación había mejorado, ya que la Caja de Conversión era un ente que ejercería menos presión sobre ellos que el Banco Nación con sus problemas propios de liquidez.

\section{El Instituto Movilizador de Inversiones Bancarias y el Banco Español}

En 1935 el gobierno argentino decidió avanzar en lo que consideraba sería una refundación del sistema financiero y monetario argentino. Se creaba el Banco Central, en teoría un organismo independiente y autónomo que asumiría las facultades de emisión y supervisión, control monetario y otorgamiento de redescuentos, funciones antes en manos de la Caja de Conversión y del Banco Nación. Una de las medidas previas requeridas para lograr esta refundación era sanear el sistema bancario mediante el cierre de varias entidades privadas con dificultades estructurales en sus carteras de créditos (todas muy endeudadas con el Banco Nación). Estas fueron el Banco Argentino Uruguayo, la sección financiera de la Sociedad Ernesto Tornquist, El Banco Hogar Argentino y, en especial, el Banco Español. Las carteras de baja cobrabilidad de estos bancos y las propiedades recibidas por hipotecas ejecutadas serían trasferidas a una nueva institución pública, el Instituto Movilizador de Inversiones Bancarias, que se encargaría de los cobros residuales y el remate de las propiedades recibidas. Con este esquema, explicaría Prebisch, se buscaba generar un nuevo sistema financiero que "no partiera de una situación de podredumbre, había que extirpar del organismo todo lo que estaba carcomido y comenzar de nuevo” (Magariños, 1991, pp. 114-115). En alguna medida la función del Instituto Movilizador era absorber las deudas morosas de la clase política, como lo señalaría un diputado demócrata progresista, para quien los créditos trasferidos eran "deudas de políticos fundidos que siempre vivieron del crédito oficial" (BCRA, 1972, II, p. 1072). En el nuevo establecimiento los préstamos morosos estarían mejor protegidos de toda investigación parlamentaria y periodística, situación amparada por todos los actores multipartidarios involucrados, en una actitud común que Prebisch denominaría "solidaridad política ilimitada 
entre deudores y bancos" (Mallorquín, 2006, p. 38). Tiempo después, Prebisch se lamentaría que el acta fundacional del Instituto Movilizador (que tuvo un carácter casi secreto) y que describía esta situación de "verdad histórica extrema", se hubiera perdido pese a sus esfuerzos posteriores por ubicarla (Magariños, 1991, pp. 116-117). También han desaparecido los listados de los deudores del Instituto. El primer libro de actas de la institución -único volumen sobreviviente- presenta información fragmentada.

La reforma financiera implicaba que el Estado absorbía las deudas morosas de los bancos en situación crítica, los que deberían cerrar sus puertas. La cartera adquirida fue de 384000000 de pesos, de los cuales 71 \% correspondía al Banco Español y el resto a los bancos El Hogar Argentino, el Argentino-Uruguayo y el Tornquist. ${ }^{11}$ Para el Banco Español la cartera trasferida fue el equivalente al total de los préstamos otorgados en curso ${ }^{12}$ Pese a la magnitud de los montos traspasados, se permitió al establecimiento continuar operando, ya que no sólo se le compró su cartera mala, sino que se le entregaron las cuentas corrientes saludables de las otras instituciones, que fueron discontinuadas. La entidad estaba demasiado vinculada con la clase política como para cerrarla, lo que hubiera sido lo lógico dado su comportamiento previo. Para Prebisch esta situación fue escandalosa. No sólo se dejaba a los antiguos gestores de la entidad impunes, sino que se les encomendaba la gestión del banco en su nueva etapa. Cuando Prebisch tomó conciencia de lo que estaba ocurriendo se dirigió al ministro de Hacienda, Federico Pinedo, y le rogó: "Doctor Pinedo, no haga esto, porque usted va a ir a parar a la cárcel algún día; lo van a acusar de esto. Y el [...] gerente general del Banco Español, que había tolerado todas estas cosas y las había apañado irá a visitarlo de tiempo en tiempo, pasándole por las rejas una botella de cerveza. Eso va a ser” (Magariños, 1991, p. 116).

Pero el poder de lobby de los antiguos administradores del Banco sustentado en la cantidad de créditos blandos otorgados a personajes políticos o sus familiares garantizaba que se mantuviera el statu quo anterior. Entre los posibles afectados por cualquier cambio drástico estaba el mismo presidente, Agustín P. Justo, endeudado por una fuerte suma con la entidad, lo mismo que su vicepresidente Julio Roca (por un monto menor) ${ }^{13}$ Asimismo, según Prebisch muchos legisladores estaban amordazados en sus opiniones por sus deudas, ya que serían trasferidas al Instituto Movilizador donde esperaban contar con un tratamiento benévolo (Magariños, 1991, p 117). A la cabeza del Instituto se designó a Celedonio Pereda (h.), un político conservador que había sido miembro del directorio del Banco Español. ${ }^{14}$ Como subgerente del organismo se nombró a Miguel Mibelli, quien se desempeñó como contador general del Banco Español entre 1923 y 1929 (Sammartino, 1938, p. 14). Por otra parte, Eduardo Grané, gerente general del Banco Español, pasaría, en 1937, a formar parte del directorio del Banco Centra ${ }^{15}$ en representación de los ban-

${ }^{11}$ Para un análisis de las cifras implicadas y sus destinatarios, véase Della Paolera y Taylor (2003, pp. 285-287).

${ }^{12}$ En junio de 1934 los préstamos ascendían a 286000000 de pesos, véase Iglesias (2012, p. 63).

${ }^{13}$ La deuda de Agustín P. Justo en 1936 ascendía a 253923 pesos. En ese mes había logrado que el banco le refinanciara a diez años su pasivo, cuyo principal sólo debería comenzar a repagar en 1946. Véase BCERP, 1936-1941, 20 de octubre de 1936, pp. 24-25. Dos años después el banco registraba que Justo (ya finalizada su presidencia) no había pagado los intereses de su deuda, lo que representa una clara situación de morosidad. La entidad no tomó acciones en su contra. Véase BCERP, 1936-1941, 28 de junio de 1938, p. 278. En 1938 Julio Roca contaba con un crédito moroso por 42328 pesos. Véase BCERP, 1936-1941, 6 de septiembre de 1938, p. 365.

${ }^{14}$ Exmiembro del directorio del Banco Español, entre 1919 y 1930. Además, Celedonio Pereda (h.) fue miembro del directorio de las Bodegas y Viñedos Giol, empresa dependiente del Banco Español, entre 1919 y 1935 . A ese directorio renunció en 1935 al tomar la presidencia del Instituto Movilizador de Inversiones Bancarias.

${ }^{15}$ Grané permaneció en el cargo hasta 1945. Entre 1952 y 1962 se desempeñó como presidente del Banco Español. 
cos privados de capitales argentinos; es decir, se trasformó en una autoridad para Raúl Prebisch, para entonces gerente general de la entidad oficial. Todo el asunto del Banco Español dejó un recuerdo muy amargo en Prebisch, quien incluso postuló que quizá dejar caer a los bancos privados de facto quebrados durante la depresión hubiera sido una buena opción, así terminaría con una situación de mala gestión, corrupción e ineficiencia, que se mantendría en el futuro (Magariños, 1991, pp. 108 y 115).

Con el advenimiento del peronismo, la situación del Banco Español mejoraría, al aflojarse aún más el control y las restricciones que se le habían impuesto en 1935, como el de limitar sus dividendos. Por su parte, sus antiguos deudores políticos, ahora deudores del Instituto Movilizador, lograrían que se continuaran ampliando los plazos de reembolso de sus créditos, mientras que la inflación iniciada hacia 1943 se iría encargando de licuar sus montos (Mallorquín, 2006, p. 38). El Banco Español continuaría funcionando con sobresaltos hasta la década en 1980, durante la cual fue disuelto por no poder continuar operando debido a su cartera crediticia morosa. Su caída se desencadenó cuando el Banco Central le denegó un redescuento que salvaría a la entidad de su situación crítica en ese momento (Newland, 2015, p. 88).

\section{Algunos casos de créditos políticos otorgados Por El Banco EsPaÑol}

Antes de avanzar sobre algunos casos de créditos otorgados a políticos o a sus propias empresas por el Banco Español es útil dimensionar las cifras que se estarán mencionando en el texto. Un monto que parece repetirse es el de 1000000 de pesos. ¿Cuál era el valor de esa suma, por ejemplo en 1935? Si se contrasta la cifra con los importes de los campos en Argentina en ese año se puede determinar que con 1000000 de pesos se podía comprar una estancia de 8000 hectáreas (de productividad media) en la Provincia de Buenos Aires o de 50000 hectáreas en Corrientes o de 150000 en Santiago del Estero ${ }^{16}$ Con la misma suma se podrían adquirir 50 casas barriales en la ciudad de Buenos Aires o pagar los sueldos de una empleada doméstica durante 2000 años, los emolumentos de un obrero a lo largo de 500 años o de un albañil o docente porteño durante 350 años. Es decir, se trataba de montos enormes que terminaron siendo transferencias directas a sus beneficiarios.

El crédito otorgado por el Banco Español a Lisandro De la Torre es un ejemplo de cómo la política interfería en el sistema financiero. De la Torre era el fundador del partido Demócrata Progresista de Santa Fe, que fue diputado nacional entre 1912 y 1916 y entre 1922 y 1925, y senador nacional entre 1932 y 1936. Por sus denuncias contra el Pacto Roca-Runciman recibió el calificativo de "fiscal de la patria”, siendo en teoría un emblema contra todo acuerdo y práctica corrupta. Sin embargo, su larga relación personal con el Banco Español pondría en evidencia una permeabilidad a la obtención de ventajas originadas en su poder político. Su relación con la entidad financiera existió al menos desde 1912, cuando se presentó como candidato a gobernador de la Provincia de Santa Fe, acompañado por el candidato a vicegobernador Cornelio Casablanca, un alto funcionario de la sucursal del Banco Español en Rosario. En 1913, De la Torre presentaría en el congreso el proyecto de ley por la cual se permitía a la Caja de Conversión descontar documentos de deuda de particulares pertenecientes a bancos privados (con la intermediación del

\footnotetext{
${ }^{16}$ Véanse los precios de la tierra y las remuneraciones en los periódicos La Nación y La Prensa correspondientes a junio de 1935.
} 
Banco Nación) ${ }^{17}$ En la práctica implicaba, en momentos de necesidad perentoria de fondos, que las entidades privadas pudieran acceder a financiamiento rápido, poniendo como colaterales los créditos que habían otorgado. La legislación habilitaría la posibilidad de enormes subsidios públicos a los bancos privados, en especial cuando la tasa de interés a la que se le prestaban fondos fuera menor a la de mercado. Tiempo después, Juan B. Justo acusaría a De la Torre de haber tenido como punto principal de su programa político el de dinero barato para los bancos y que con la ley había abierto la puerta para que el gobierno cometiera en el futuro "tremendas barrabasadas" en el ámbito financiero. ${ }^{18}$ A pocos años de aprobada la ley, el Banco Español, el mayor beneficiario de los redescuentos, otorgaba a De la Torre un crédito sin garantías y a un bajo interés para la adquisición del control de una estancia de 78000 hectáreas ubicada en el noroeste de Córdoba (Larra, 1950, p. 210) ${ }^{19}$ De la Torre obtuvo sumas adicionales sobre la propiedad lo que hizo que su deuda al menos se triplicara acercándose a 1000000 de pesos (Viale, 1931). Con el tiempo se volvería un deudor moroso sin abonar los intereses ni el capital ${ }^{20}$ Cuando pudo, el Banco Español utilizó este crédito de difícil o imposible cobro como garantía de los redescuentos obtenidos del Banco Nación, que así quedaba como virtual propietario de la deuda. Cuando Prebisch -como subsecretario de Hacienda- preparaba en 1934 la estrategia de aprobación del Banco Central y del Instituto Movilizador de Inversiones Bancarias temió una embestida al proyecto en el Congreso por parte del senador De la Torre, quien era esperable que se opusieraía a una iniciativa que incrementaba la injerencia del poder estatal nacional en el ámbito financiero. No obstante, el abogado jefe del Banco Español informó a Prebisch que no debía preocuparse en cuanto al Instituto Movilizador, ya que De la Torre le manifestó que no lo atacaría. La razón era que en algún momento se transformaría en deudor de la institución, y no quería desacreditarse con el organismo que en el futuro sería su acreedor (Mallorquín, 2006, p. 38). La situación morosa de De la Torre continuaría. Y el Instituto Movilizador -desde 1935 nuevo titular del crédito- encargaría al Banco Español su gestión. A De la Torre, ya casi retirado de la política, se le ofreció a tomar al establecimiento rural como pago total del crédito, que dado su valor en ese momento implicaba cubrir sólo lo adeudado parcialmente, pero no aceptó porque consideraba su situación económica personal insalvable ${ }^{21}$ El estado general de depresión de De la Torre lo llevaría al suicidio en enero de1939 (véase Larra, 1950, pp. 202-203).

Un caso de dimensión gigantesca fue el de Robustiano Patrón Costas, el más importante político conservador de la época. Fue gobernador de Salta entre 1913 y 1916, senador nacional entre 1916-1925, 1932-1938 y 1938-1943 y presidente provisional del Senado en el lapso 19321943. Uno de los fundadores -en 1931- del agrupamiento de partidos conservadores de todo el

\footnotetext{
${ }^{17}$ Ese mismo año el gerente del Banco Español publicaba un folleto argumentando la necesidad de una nueva legislación sobre redescuentos. Véase Coelho (1913).

${ }^{18}$ Debe reconocerse que el proyecto inicial de Ley de Redescuentos presentado por De la Torre era más restrictivo que la legislación finalmente aprobada, ya que aplicaba una tasa de interés de mercado a los redescuentos que sólo podían ser de corto plazo. Véase “El Senador Justo habló en el cine Ideal”, La Vanguardia, 18 de marzo de 1926, p. 1, y Torre (1941, pp. 11-57).

${ }^{19}$ Se ha mencionado también que el préstamo fue una retribución por un juicio millonario que De la Torre hizo ganar al Banco Español. Véase L. Merli, Lisandro de la Torre: Crónica de un suicidio patriótico. Recuperado de http://www.rodolfowalsh.org/spip.php?article2417.

${ }^{20}$ Sobre la situación crediticia irregular de De la Torre con el Banco Nación y el Banco de la Provincia de Buenos Aires, véase Unamuno (1988, pp. 100-103).

${ }^{21}$ De la Torre había intentado sin éxito vender la estancia para cubrir el monto de la deuda. Véase Torre (1932, p. 169).
} 
país en el Partido Demócrata Nacional donde se desempeñó como su primer presidente. Patrón Costas también ejercía un papel empresarial fuerte, en especial luego de crear en Salta, en 1918, el enorme ingenio San Martín de Tabacal. Esta empresa se financió con generosos recursos aportados en última instancia por la banca pública. Por ello, Patrón Costas sería señalado como "el deudor máximo de los bancos oficiales" (BCRA, 1972, II, p. 996). Para obtener los fondos iniciales para su emprendimiento azucarero fue vital la participación de Domingo Salaberry, un importante consignatario agropecuario que se desempeñó como ministro de Hacienda de Hipólito Yrigoyen durante todo su primer mandato. Salaberry, junto con miembros de su familia regenteaba una empresa consignataria que, como era usual en la época, también cumplía funciones financieras. Esta entidad obtendría generosos aportes monetarios del Banco Nación que a su vez serían trasferidos a una sociedad creada por Patrón Costas para adquirir y desarrollar el ingenio. En la nueva sociedad, denominada Patrón Costas, Bercetche y Mosoteguy, Patrón Costas tuvo como socios a los dos cuñados de Salaberry, Pedro Mosoteguy y Pedro Bercetche. La empresa azucarera también obtendría créditos de otras entidades financieras como el Banco de la Provincia de Buenos Aires y el Banco Español. Con el tiempo, y tras la crisis ganadera de 1921, la consignataria de Salaberry entraría en serias dificultades financieras, por lo que sus créditos serían trasferidos al Banco Nación. Esta situación de quebranto, junto con acusaciones de corrupción, llevarían a Salaberry al suicido en 1923 (BCRA, 1972, II, pp. 1121-1122). ${ }^{22}$ La deuda contraída por Patrón Costas, ahora en manos del Banco Nación (que lideraba un consorcio de acreedores) siempre tendría tratamiento "político". Cuando la entidad decidió tratar en una reunión de directorio la cuestión de su ejecución o cobro dada su situación de morosidad, recibió una nota del presidente Yrigoyen que indicaba renovar el crédito impago en las condiciones favorables en que se encontraba (BCRA, 1972, II, p. 1152). Según Juan B. Justo la dependencia financiera del salteño de la banca estatal hizo que limitara sus críticas al gobierno radical. Según el socialista, el político conservador "se hace el ciego, el mudo y el zonzo frente a las macanas del gobierno de Yrigoyen!” (Torres, 1973, p. 56). La deuda total de Patrón Costas, Bercetche y Mosoteguy rondaría los 50000000 de pesos (moneda nacional) para $1933{ }^{23}$ La suma crecía de manera constante debido a que la sociedad no abonaba las amortizaciones ni los intereses correspondientes e inclusive tomaba nuevos créditos ${ }^{24}$ Con el Banco Español su pasivo era de 4500000 de pesos en 1924 25 y presume duplicado para 1938. El caso de la deuda de Patrón Costas fue denunciado por Nicolás Repetto, diputado socialista, en los debates sobre la creación del Instituto Movilizador en la Cámara de Diputados en 1935. Repetto indicó que era inaceptable que Patrón Costas recibiera continuos favores del Estado, lo que era un indicador de la profunda corrupción existente en el sistema político. Lo peor para Repetto era que intereses personales y materiales condicionaran las votaciones de un legislador (1972, II, p. 1152). Las deudas bancarias de Patrón Costas, Bercetche y Mosoteguy pasarían al Instituto Movilizador, lo que incluía los créditos otorgados por el Banco Español.

\footnotetext{
${ }^{22}$ Sobre Salaberry y la corrupción, véase también Solberg (1979), p. 73 y Senado de la Nación (1926), p. 5.

${ }^{23}$ Según Horacio Oyhanarte, durante el Gobierno del General Uriburu (amigo de Patrón Costas) se realizó una quita de la deuda de 9000000 de pesos. Ver Unamuno (1988), p. 91.

${ }^{24}$ Véanse Banco de la Nación Argentina (27 de diciembre de 1924, p. 192) y Berp (1924-1935, 19 de diciembre de 1933, p. 61).

${ }^{25}$ Véase BerP (1924-1935, 14 de diciembre de 1926, p. 198). La deuda total de Patrón Costas, Bercetche y Mosoteguy con el consorcio bancario acreedor en 1926 era de 12000000 de pesos oro o 30000000 de pesos moneda nacional (BERP, 1924-1935, 17 de diciembre de 1926, p. 201). Véase también Banco de la Nación Argentina (27 de diciembre de 1924 p. 192).
} 
Otro caso de un crédito del Banco Español otorgado a un político influyente fue aquel percibido por Antonio Santamarina. Este era un gran estanciero y dirigente conservador de larga trayectoria: diputado nacional entre 1908 y 1924 y entre 1926 y 1930, y senador nacional entre 1932 y 194326 Santamarina conformaría (representando el ala conservadora) junto a Federico Pinedo (por el socialismo independiente) el grupo político-civil que acompañaría el golpe militar contra Yrigoyen. En sus relaciones con el Banco Nación y el Banco Español, sin duda fue de gran auxilio su hermano Jorge Santamarina, quien luego de haber sido miembro del directorio del Banco Español, entre 1920 y 1931 ${ }^{27}$ pasó a formar parte del directorio del Banco Nación, del cual fue vicepresidente en 1932 y presidente entre 1933 y 19432 La red familiar se completaba con un tercer hermano, Enrique, que fue miembro del directorio del Banco Nación entre 1917 y 1927, a la vez que vicepresidente de Argentina durante el gobierno del general Uriburu 29 La sumatoria de los créditos sin garantía que Antonio Santamarina logró del Banco Español es cercana a 1000000 de pesos ${ }^{30}$ a la que se adicionaba otro préstamo más grande obtenido del Banco Nación ${ }^{31}$ El crédito terminaría, en 1935, en manos del Instituto Movilizador: aunque la deuda fue trasferida al Estado, se encomendaría al Banco Español su gestión y cobro. Por ello se sabe que en 1938 se permitió que uno de los pagos fuera destinado a descontar el capital adeudado, en lugar de aplicarse a abonar los intereses impagos, que era lo que correspondía ${ }^{32}$ Unos meses más tarde el Banco Nación solicitaba que a otro pago de Santamarina se le aplicara de nuevo el mismo tratamiento (que era el que se le daba en el caso del crédito del Banco Nación), aunque esta vez la solicitud fue denegada ${ }^{33}$ Otro político conservador beneficiado por el sistema fue Samuel Ortiz Basualdo, presidente de la Caja de Conversión en 1930, diputado nacional por la Provincia de Buenos Aires entre 1936 y 1940 y entre 1942 y 1943, y miembro del directorio del Banco Español entre 1924 y 1936. Ortiz Basualdo no sólo tenía una deuda a título personal ${ }^{34}$ sino que también la sucesión de su madre (de la que era parte) contaba con un crédito (trasferido al Instituto Movilizador) por 633038 pesos ${ }^{35}$ El cuadro se completaba con la suma prestada por el Banco Español a su hermana Ana Teresa Ortiz Basualdo por 1723530 pesos, deuda que también acabó en el Instituto Movilizador ${ }^{36}$ A todos ellos se agrega Matías Sánchez Sorondo, destacado político conservador y nacionalista, fue diputado (1918-1926), senador (1932-1941), y ministro del Interior durante el gobierno de Uriburu. Durante varios años fue contratado como abogado y asesor

\footnotetext{
${ }^{26}$ Propietario de la estancia Dos Hermanos en Tandil. En el mismo partido y con otros socios era dueño de la estancia Bellavista.

${ }^{27}$ Era claro de que era un miembro influyente del directorio, ya que también fue nombrado miembro del directorio de Bodegas Giol (al menos en 1931). Cámara Argentina de Sociedades Anónimas (1931, p. 516).

${ }^{28}$ También sería miembro del directorio del Banco Central entre 1937 y 1943, una entidad que debía controlar (y otorgar redescuentos) al Banco Español.

${ }^{29}$ Uno de sus hijos, Enrique Santamarina (h.) fue también miembro del directorio del Banco Español, entre 1936 y 1939, y su síndico en 1940.

${ }^{30}$ BCERP (1936-1941, 16 de marzo de 1937, pp. 162-163).

${ }^{31}$ En el libro de Actas del Banco Español consta que tenía una deuda hipotecaria de 1007822 pesos a la que se adicionaba otra mayor con el Banco Nación, de la que no se menciona la cifra. Banco Español y del Río de la Plata Limitado (BERPL, 1936-1942, 4 de noviembre de 1937, libro 2, p. 217).

${ }^{32}$ Véase BERPL (1936-1942, 12 de agosto de 1937, libro 2, pp. 115-116; 2 de junio de 1938, libro 3, p. 5).

${ }^{33}$ Para 1942 el político cancelaba la deuda con el Instituto Movilizador originada en el préstamo del Banco Español. BERPL (29 de enero de 1942, libro 5, p. 474; 10 de noviembre de 1938, p. 207).

${ }^{34}$ Monto desconocido. BERPL (1936-1942, 17 de junio de 1937, libro 1, p. 59).

35 BERPL (1936-1942, 22 de abril de 1937, libro 1, p. 478).

36 BERPL (1936-1942, 30 de septiembre de 1937, libro 1, p. 176).
} 
por el Banco Español, manteniendo esta relación hasta 1937. Tomaría fondos en préstamo de la sucursal del Banco Español en París. Para 1937 su deuda morosa con la entidad era de 1000000 de francos 37

En la lista de deudores del Banco Español pasados al Instituto Movilizador no se puede dejar de mencionar tres destacadísimos políticos radicales, Marcelo T. de Alvear (presidente de la Nación de 1922 a 1928), Carlos Noel (intendente de Buenos Aires entre 1922 y 1927 y presidente de la Cámara de Diputados entre 1936 y 1938), y Manuel de Iriondo (presidente del Banco Nación entre 1910 y 1918, ministro de Justicia en 1932-1937, y gobernador de Santa Fe de 1937 a 1941). ${ }^{38}$ A estas figuras se suma la de Honorio Pueyrredon, ministro de Agricultura y de Relaciones Exteriores durante el primer gobierno de Hipólito Yrigoyen y luego embajador argentino ante Estados Unidos, Cuba y la Sociedad de las Naciones 39

En 1911 el Banco Español adquiría la mayoría accionaria de la sociedad Bodegas y Viñedos Giol, una empresa vitivinícola de Mendoza que sería considerada de las más grandes del mundo. Desde entonces y hasta su estatización, en 1954, el Banco controlaría la firma, designando a sus propios miembros como directores de Giol ${ }^{40}$ Para estos el cargo era una fuente interesante adicional de ingresos, ya que percibían parte de las utilidades como remuneración. Ya en 1923 el Banco Español había logrado que el Banco Nación le otorgara redescuentos con base en la deuda de Giol (en su posesión) por 11000000 de pesos ${ }^{41}$ Para 1936 el monto adeudado por la bodega al Banco Español era de 19000000 de pesos, suma trasferida al Instituto Movilizador. Cuando en su primer año de vida el organismo era presionado por la opinión pública para controlar a sus deudores, puso más presión sobre el Banco Español, que seguía administrando el crédito, para que procediera a su cobro o renegociación en términos aceptables del punto de vista financiero. El Banco entonces firmó un acuerdo de pago con la Giol por el que se estipulaba que debía efectuar un desembolso mensual fijo con un plazo de 20 años, determinando que todas la utilidades generadas en el lapso debían ser destinadas al pago del capital adeudado, y que no se podían pagar dividendos mientras persistiera la deuda, ni tomar créditos bancarios adicionales ${ }^{42}$ Es claro que el convenio sirvió para ser remitido al Instituto Movilizador como muestra de una falsa determinación enérgica del Banco, que más adelante relajaría la cláusula de pago del principal permitiendo que las utilidades se utilizaran para la creación de reservas y amortizaciones de todo tipo.43 Ade-

${ }^{37}$ BCERP (1936-1941, 7 de diciembre de 1937, p. 8).

${ }^{38}$ La deuda de Alvear era por 108406 pesos, la de Noel por 133400 pesos y la de De Iriondo por 121733 pesos, véase Argentina. Instituto Movilizador de Inversiones Bancarias (16 de junio de 1936, pp. 202, 204). En 1941 el Banco Español declaraba la especial vinculación existente con Alvear para permitirle, como excepción señaladísima hacer un cambio de un terreno hipotecado por otro no hipotecado. Véase BCERP (1936-1941, 2 de septiembre de 1941, p. 107).

${ }^{39}$ La deuda de Honorio Pueyrredon (prácticamente sin garantías) en 1937 con el Banco Español ascendía a 415046 pesos. BCERP (1936-1941, 18 de mayo de 1937, p. 233). En el acta se menciona su endeudamiento con muchos otros bancos.

${ }^{40}$ En 1931, por ejemplo, compartían directorios Ramiro Fernández de Villota, Samuel Ortiz Basualdo, Timoteo Balbín, Celedonio Pereda (h.), Guillermo Udaondo, Federico Córdoba, Casto Orbes y Jorge Santamarina. Véase Cámara Argentina de Sociedades Anónimas (1931, pp. 217 y 516). En 1935 se repiten Samuel Ortiz Basualdo, Timoteo Balbín, Guillermo Udaondo, Federico Córdoba y Casto Orbes. A estos se agregaban en ambos directorios José Mouriño y Graciano Alvear. Véase Cámara Argentina de Sociedades Anónimas (1935, pp. 214 y 221). Hacia 1938 estaban presentes en ambos directorios Timoteo Balbín, Ezequiel García, Casto Orbes y Eduardo Grané. Véase Sammartino (1938, pp. 27-28).

${ }^{41}$ Banco de la Nación Argentina (13 de diciembre de 1923, p. 191).

42 BERPL (1936-1942, 1 de octubre de 1936, p. 238; 8 de octubre de 1936, pp. 243-244).

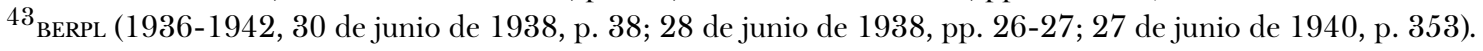


más, se le permitió descontar documentos de sus proveedores en el Banco, lo que iba en contra de la cláusula de no aumento de deuda ${ }^{44}$ Por su parte, para no generar beneficios que debieran ser remitidos al Estado, los miembros del directorio crearon Quindemil y Compañía, empresa paralela distribuidora de vinos, que recibía el producto a bajo costo y lo vendía a precio de mercado. Así la ganancia quedaba en manos de los miembros del directorio, mientras que el acreedor estatal era burlado (Sammartino, 1938, p. 11). Casi cumplido el plazo de los 20 años en que Giol debía cancelar su deuda con el Estado, la empresa fue trasferida a la Provincia de Mendoza.

Para los miembros de la clase política endeudada y morosa su situación crediticia los dejaba muy expuestos en caso de perder poder personal o en caso de acceder al poder ejecutivo un grupo político no tradicional. Los socialistas - los mayores denunciantes y críticos de la corrupción bancaria- señalaban que Robustiano Patrón Costas debía seguir en política (por ejemplo como perenne candidato a presidente) por su necesidad de continuar con un tratamiento benévolo en cuanto a sus deudas (BCRA, 1972, II, p. 996). Esta vulnerabilidad aumentó con la llegada de Juan Domingo Perón al gobierno, a partir de 1943, ya que implicaba que un nuevo y distinto grupo social controlara al Estado. Cuenta Raúl Prebisch que en esa época un personaje político tradicional (pensamos que fue Patrón Costas o Antonio Santamarina) le expresó sus temores sobre cómo sería tratada la cuestión de su crédito por el trato favorable recibido por el Instituto Movilizador en cuanto a la tasa de interés aplicada y el plazo de repago. Sin embargo, y pese a que sin duda la persona era un opositor a Perón, el gobierno no tomó medida en su contra, ni respecto a los otros deudores ${ }^{45}$ Es evidente que la situación de morosidad de muchos opositores a Perón con el Instituto Movilizador fue un letal recurso de disciplinamiento con que contaba el nuevo régimen respecto a figuras muy notables de la oposición.

\section{Conclusión}

El control que la clase política poseía sobre la banca pública y las transferencias o subsidios estatales a lo largo del periodo de entreguerras en Argentina conllevó a una variedad de prácticas oportunistas bajo la forma de una apropiación directa o indirecta de recursos públicos. Los créditos otorgados a personajes influyentes condicionaron su acción política, y así perdieron independencia y ecuanimidad. No era lo mismo enfrentar al partido en el gobierno en los casos en que existían (o no existían) pasivos ejecutables anclados en instituciones financieras dependientes del poder ejecutivo. Los préstamos otorgados con criterios políticos y de amiguismo no sólo distorsionaron la práctica política y el uso de los fondos financieros, sino que empeoraron la distribución de la riqueza del país.

La gran reforma institucional bancaria y monetaria de mediados de la década de 1930 buscó alterar el marco institucional y los incentivos para así lograr una mejora en la eficiencia financiera. Pero la realidad parece haber sido más bien de continuidad que de cambio al menos en el caso del comportamiento del Banco Español. En este artículo sólo se ha expuesto una muestra de lo que fue el sistema, reconstruido sobre los escasos rastros que dejaron algunos trámites crediticios. Queda pendiente una investigación de mayor envergadura sobre el otro establecimiento que otor-

\footnotetext{
${ }^{44}$ En específico, se autorizó a la sucursal Mendoza del banco a descontar documentos de Giol hasta por 500000 pesos (BERPL, 1936-1942, 5 de noviembre de 1936, p. 273).

${ }^{45}$ Prebish indica que el personaje era de relevancia pública, muy vinculado al Banco Español. Magariños (1991, p. 116). Perón había señalado a Antonio Santamarina como un gran representante del conservadurismo, que incluso se había unido con los comunistas en la Unión Democrática, en 1946, para enfrentarlo. Véase Martínez (1996, p. 218).
} 
gó una gran cantidad de préstamos blandos, el Banco Nación, y cuya magnitud se desconoce ${ }^{46}$ Sin duda la situación atravesada por el Banco Español no ha sido excepcional en Argentina, aunque lamentablemente no existen muchos estudios de tipo histórico enfocados en el tema. ${ }^{47}$

\section{LISTA DE REFERENCIAS}

Argentina. Instituto Movilizador de Inversiones Bancarias (1936). Actas del Directorio (Libro I). Buenos Aires: Autor.

Banco Central de la República Argentina (1972). La creación del Banco Central y la experiencia monetaria argentina entre los años 1935-1943. Buenos Aires: Autor.

Banco Crédito Español y del Río de La Plata (1936-1941). Libro de Actas del Directorio y de las Asambleas Generales. Buenos Aires: Autor.

Banco de la Nación Argentina (1923-1924). Libro de Actas (núms. 206 y 209). Buenos Aires: Autor.

Banco Español del Río de la Plata (1919). Memoria y balance cerrado el 30 de junio de 1919. Buenos Aires: Autor.

Banco Español del Río de la Plata (1986). Banco Español. Una memoria de 100 años. Buenos Aires: Autor.

Banco Español y del Río de La Plata (1924-1935). Libro de Actas del Directorio y Asambleas Generales. Buenos Aires: Autor.

Banco Español y del Río de la Plata Limitado (1936-1942). Libro de Actas del Directorio y Asambleas Generales (vols. 1, 2, 3, 5). Buenos Aires: Autor.

Calomiris, Ch. y Haber, S. (2014). Fragile by design: The political origins of banking crises and scarce credit. Estados Unidos: Princeton.

Cámara Argentina de Sociedades Anónimas (1931). Guía de Sociedades Anónimas 1930-1931. Buenos Aires: Autor.

Cámara Argentina de Sociedades Anónimas (1935). Guía de Sociedades Anónimas 1934-1935. Buenos Aires: Autor.

Coelho, A. J. (1913). Los problemas económicos de la República Argentina la emisión fiduciaria y el redescuento. París: s. e.

Della Paolera, G. y Taylor, A. M. (2003). Tensando el ancla: La caja de conversión argentina y la búsqueda de la estabilidad macroeconómica, 1880-1935. Buenos Aires: Fondo de Cultura Económica de Argentina.

El Senador Justo habló en el Cine Ideal. (1926, marzo 18). La Vanguardia, 1.

Estadística bancaria, año 1935 (1936, febrero). La Argentina Económica, 548.

Falta de garantía y seriedad del Banco Español del Rio de la Plata (1927, octubre). Revista Sudamericana de Bancos, Ferrocarriles, Seguros y Comercio, 551, 1-2.

Fernández, J. A. (1912). La Banca Argentina, su actuación y desarrollo. El Banco Español del Río de la Plata. Buenos Aires: s. e.

Iglesias, M. (2012). El Banco Español del Río de la Plata en sus primeros 50 años, 1886-1935. Revista Electrónica de Fuentes y Archivos, 3(3), 47-73.

\footnotetext{
${ }^{46}$ Según Horacio Oyhanarte, la cifra de créditos privilegiados e insolventes otorgados por el Banco Nación a quince o 20 deudores rondaba los 250000000 de pesos hacia 1931. Véase Unamuno (1988), p. 92.

${ }^{47}$ Excepciones son Lotersztain (2010) y Quintela (2005). Una obra general que cubre la historia de la corrupción en Argentina, incluyendo al sector bancario es la de GuillermoVitelli (2006).
} 
Justo, J. B. (1927, septiembre). Operaciones bancarias fraudulentas. Revista Sudamericana de Bancos, Ferrocarriles, Seguros y Comercio.

Larra, R. (1950). Lisandro de la Torre: Vida y drama del solitario de Pinas. Buenos Aires: Hemisferio.

Lotersztain, I. (2010). Los bancos se roban con firmas: Corrupción y crisis en 1890. Buenos Aires: Turmalina.

Magariños, M. (1991). Diálogos con Raúl Prebisch. México: Banco Nacional de Comercio Exterior/Fondo de Cultura Económica.

Mallorquín, C. (2006). Textos para el estudio del pensamiento de Raúl Prebisch. Cinta de Moebio. Revista de Epistemología de Ciencias Sociales, 25, 17-63.

Martínez, M. (1975). El país, el dinero y los hombres. Buenos Aires: Theoria.

Martínez, T. E. (1996). Las memorias del general. Buenos Aires: Planeta.

Newland, C. (2015). Sobre las estrategias, utilidades y valuación del grupo Garovaglio y Zorraquín durante el siglo xx. Revista de Historia Industrial, 60, 81-102.

Quintela, R. L. (2005). Crisis bancarias y corrupción. Buenos Aires: Dunken.

Regalsky, A. e Iglesias, M. (2015). Banca pública, banca privada y crisis: El Banco de la Nación Argentina como prestamista de última instancia entre la Primera Guerra Mundial y la posguerra. Ensayos Económicos, 72, 103-138.

Sammartino, E. (1938). Como cumplio sus fines el Instituto movilizador. Buenos Aires: s. e.

Senado de la Nación. Argentina (1926). Proyecto de nombramiento de una Comisión Investigadora en el Banco de La Nación Argentina. Buenos Aires: Autor.

Solberg, C. E. (1979). Oil and nationalism in Argentina: A history. Stanford: Stanford University Press.

Torre, L. (1932). Cartas de Lisandro de la Torre. Bueno Aires: s. e.

Torre, L. (1941). Cuestiones monetarias y financieras. Buenos Aires: s. e.

Torres, J. L. (1973). La oligarquía maléfica (autopsia de un cadáver político). Buenos Aires: Freeland.

Unamuno, M. (1988). Horacio Oyhanarte y el golpe militar de 1930. Buenos Aires: Centro Editor de América Latina.

Viale, A. (1931). El dr. Lisandro de la Torre. Buenos Aires: s. e.

Vitelli, G. (2006). Negocios, corrupciones y política: Las repeticiones de la Argentina. Buenos Aires: Prendergast.

¿Banqueros...? (1927, octubre). Revista Sudamericana de Bancos, Ferrocarriles, Seguros y Comercio, $551,11-12$. 